\title{
Fungsi dan Tantangan Pendampingan Pastoral bagi Pasien Wanita Penderita Penyakit Kanker di Yayasan CAC (Cancer Awareness Community) Surabaya
}

\author{
Elfrida Hutagalung ${ }^{1}$, Anggia Hapsari ${ }^{2}$, Johanes Rajagukguk \\ Magister Pastoral Konseling, Sekolah Tinggi Teologi Bethel Indonesia, Jakarta \\ Adek_htg@hotmail.com, anggiahapsari@sttbi.ac.id, \\ johanesrajagukguk@sttbi.ac.id
}

\begin{abstract}
Abstrak
Seseorang yang mengalami penyakit mematikan kanker cenderung frustasi dan putus asa untuk keluar dari penyakit itu. Selain peluang kesembuhannya yang kecil, biaya perawatan dan terapi amat mahal sehingga hanya kalangan tertentu saja yang dapat mengaksesnya. Yayasan CAC Surabaya adalah salah satu bentuk pelayanan yang menjawab persoalan itu. Pasien penderita kanker yang dilayani bukan hanya secara medis, tetapi mereka juga melakukan pendampingan dengan mendatangkan para hamba Tuhan dan konselor untuk mendampingi. Mereka membantu dengan menyediakan tempat tinggal sementara atau rumah singgah dan biaya pengobatan semampu yang mereka bisa berikan. Tujuan penelitian ini adalah untuk mendapatkan model pendampingan pastoral bagi penderita kanker di CAC Surabaya yang nantinya dapat diterapkan secara umum. Metode yang digunakan adalah kualitatif dengan sumber data adalah wawancara mendalam kepada pasien dan pengelola Yayasan CAC Surabaya. Hasil penelitian menunjukkan fungsi pendampingan pastoral terdapat dalam rekonsiliasi, penyembuhan, dan peneguhan. Sedangkan tantangan pendampingan Pastoral kepada pasien terlihat saat membangkitkan semangat dan harapan hidup pasien, meyakinkan pasien bahwa mujizat masih ada, menuntun pasien untuk percaya kuasa doa, dan membangkitkan iman pasien melalui Firman.
\end{abstract}

Kata Kunci: Kanker; CAC Surabaya; Pendampingan Pastoral

\begin{abstract}
A person who experiences the deadly disease of cancer tends to be frustrated and desperate to get out of the disease. In addition to the small chance of healing, the cost of treatment and therapy is very expensive so that only certain groups can access it. The Surabaya CAC Foundation is one form of service that answers this problem. Cancer patients are served not only medically, but they also provide assistance by bringing in God's servants and counselors to accompany them. They help by providing temporary shelter and medical expenses as much as they can afford. The purpose of this study is to obtain a model of pastoral care for cancer patients at CAC Surabaya which can later be applied in general. The method used is qualitative with the data source is in-depth interviews with patients and managers
\end{abstract}


of the Surabaya CAC Foundation. The results showed that the function of pastoral assistance is in reconciliation, healing, and affirmation. Meanwhile, the challenges of pastoral care for patients can be seen when it raises the spirit and hope of the patient's life, convinces the patient that miracles still exist, leads the patient to believe in the power of prayer, and awakens the patient's faith through the Words of God.

Keywords: Cancer; CAC Surabaya; Pastoral Assistance

\section{PENDAHULUAN}

Kesehatan memegang peranan penting dalam kehidupan manusia. Sebab tubuh yang sehat menjadi modal bagi manusia untuk dapat terus bekerja memenuhi kebutuhan hidupnya. Departemen Kesehatan RI melalui Keputusan Menteri No. 812/Menkes/SK/VII/2007 yang mengatakan terjadinya peningkatan pada pasien dengan kategori penyakit yang belum dapat disembuhkan baik pada orang dewasa dan anak seperti kanker, penyakit degeneratif merupakan tantangan yang besar dan terus meningkat yang harus kita hadapi bersama hari-hari ini (Cemy, 2012). Terkhusus kepada wanita yang pada era postmodern, terkhusus setelah masa kolonial, telah mendapatkan porsi yang besar dalam berkarya bagi bangsa dan negara (Sumual, 2016).
Penyakit kanker adalah sebuah penyakit yang belum ada obat yang mampu untuk menyembuhkan sampai hari ini. Ini disebabkan karena penyakit utamanya tidak dapat diobati dan bersifat meningkat. Pasien menjalankan pengobatan yang hanya bersifat menghilangkan gejala, keluhan, meningkatkan kualitas hidup, dan pengobatan penunjang lainnya yang dapat membantu pasien bertahan hidup lebih lama (Yafie, 1998).

Di Indonesia penyakit Kanker merupakan penyakit yang sudah banyak terjadi. Kanker terjadi disebabkan pertumbuhan sel yang begitu cepat dan melampaui batas normal sehingga tidak terkendalikan (Khosidah \& Trisnawati, 2015). Penderita penyakit kanker akan merasakan berbagai penderitaan baik secara fisik seperti nyeri, sesak 
nafas, penurunan berat badan, kemudian gangguan psikososialdan juga gangguan spiritual dimana semua gangguan diatas sangat mempengaruhi kualitas hidup penderita kanker maupun keluarganya (Maharani, 2013).

Karena itu penderita penyakit kanker tidak hanya membutuhkan pengobatan secara medis psikologis penderita kanker juga harus diperhatikan, dalam hal inilah peranan pendampingan pastoral sangat dibutuhkan. Kiesser mengungkapkan bahwa kondisi orang yang mengalami penyakit kanker akan sering mengalami pergolakan dalam hidupnya, tidak jarang seorang yang menderita sakit berada dalam ambang batas kemampuan, mempertanyakan keberadaan Allah (Johni Hardori, 2014).

Orang sakit mulai menggugat peran serta Allah dalam situasi hidupnya. Allah yang dulu penuh belas kasih kini terasa sirna bahkan Allah dirasa sudah pergi meninggalkan dia dalam penderitaan. Rasa sakit yang berat sering membuat orang sakit marah kepada Allah dan melihat Allah sebagai Allah yang bengis, kejam, dan tidak adil (Kiesser, 1984). Layaknya gugatan kemarahan karena mengalami kejadian yang tidak seharusnya dialami (Muryati et al., 2020).

Pendampingan pastoral yang dilakukan kepada orang sakit adalah sebuah pelayanan yang sifatnya pribadi (Johni Hardori, 2014). Dimana orang yang dalam keadaan sakit sedang mengalami situasi krisis dan berhadapan dengan keterbatasan diri (Romas, 2017). Proses perjumpaan antara pendamping dan orang yang akan menerima pendampingan (dalam hal ini pasien) dapat disebut sebagai pendampingan pastoral. Artinya pendampingan memiliki arti sebuah kegiatan yang dimana seseorang bersedia memberikan waktunya untuk memperhatikan, merawat, memelihara, dan melindungi kepada orang yang membutuhkan (Kusmaryanto, 2021).

Oleh karenanya, motivasi pendampingan pastoral bukanlah karena upah yang kita terima (fee), melainkan karena kasih. Pendampingan pastoral dapat juga dikatakan sebagai suatu tindakan kemanusia yang dilakukan kepada orang lain sebagai sebuah ketulusan 
dan penghayatan akan Kasih Yesus yang diterima hidupnya.

$$
\text { Bagi pasien pengidap }
$$

penyakit kanker pengalaman dan permasalahan yang dirasakan berbeda dengan orang yang menderita sakit ringan atau yang sakit karena kecelakaan. Melihat kondisi ini tentu seorang yang mengidap penyakit kanker membutuhkan pertolongan orang lain untuk dapat menemaninya melewati hari-hari terakhirnya (Storm, 2000). Menurut Campbell ada 4 fungsi Pendampingan Pastoral yang dapat dilakukan bagi penderita penyakit kanker diantaranya adalah fungsi penyembuhan, fungsi peneguhan, fungsi bimbingan, dan fungsi rekonsiliasi (Wiryasaputra \& Handayani, 2013). Keempat fungsi ini dilaksanakan dalam rangka penyembuhan secara holistik yang didalamnya terdapat pemberdayaan konsili dalam kegiatan yang dapat membangkitkan kepercayaan diri (Nugroho, 2017).

Pendampingan Pastoral ini dirasa perlu untuk dilakukan melalui praktik yang telah dilakukan oleh Cancer Awareness Community (CAC) Surabaya, layaknya pendampingan kepada anak sekolah (Sumarno, 2012) Karena itu, peneliti melakukan pra wawancara kepada penderita kanker di CAC terlebih dahulu dan didapati sebagai berikut. Wawancara ke 2 (dua) dengan Ibu Iin yang melaksanakan wawancara secara langsung pada 09 Maret 2020 di Yayasan CAC Surabaya yang menderita penyakit kanker mulut rahim stadium 3C pada tahun 2012 dan sudah menjadi seorang survivor kanker selama lebih kurang 5 tahun, namun pada tahun 2018 ternyata kanker menyebar ke usus dan dr menyarankan untuk kemoterapi tetapi Ibu Iin tidak bersedia karena merasakan pengalaman sakitnya kemoterapi. Beliau hanya meminum minuman ramuan tradisional yang ternyata tidak membawa hasil untuk kesembuhan tapi penyakit semakin berat yang mengakibatkan pendarahan.

Bersyukur karena Ibu Iin masih bisa diselamatkan dan saat ini masih menjalankan kemoterapi untuk menghentikan penyebaran sel-sel kanker di ususnya. Awal dari penyakit yang beliau rasakan adalah penyakit perut yang berulang-ulang dan melebihi dari sakit perut biasa. 
Lalu Ibu Iin mengalami masa menstruasi yang sangat panjang.

Ibu IIn merasa apa yang dialaminya biasa dan hanya makan obat-obat penghilang sakit perut saja, hingga suatu saat Ibu Iin mengalami pendarahan yang hebat dan harus opname di Rumah Sakit. Dari hasil pemeriksaan, Ibu Iin dinyatakan terkena kanker mulut rahim stadium 3C. Ketika mendengar vonis tersebut Ibu Iin merasakan ketakutan yang luar biasa, kepedihan, putus asa sampai mempertanyakan kepada Tuhan, apa dosanya. Tentu hal ini amat wajar, sebab jika melihat pada masa kini dimana Pandemi Covid-19 sedang merebak ke seluruh dunia yang menimbulkan ketakutan dan kekhawatiran (G. Pakpahan, 2020; G. K. R. Pakpahan, 2020).

Melalui latar belakang masalah tersebut di atas dan wawancara yang peneliti lakukan kepada para pasien yang sedang dalam masa perawatan di Yayasan CAC Surabaya, maka upaya pendampingan pastoral sangat dibutuhkan bagi pasien pengidap penyakit kanker.

Kehadiran pendamping pastoral bukan hanya bertujuan membantu menghilangkan rasa cemas di hati yang dialami penderita kanker, tetapi berfungsi membantu untuk mendampingi penderita untuk bertemu dengan Tuhan dalam sisa waktu hidup yang singkat, sebagaimana penulis pernah melakukan pendampingan pastoral lebih kurang 1 bulan kepada Ibu Ida yang menderita kanker Payudara (breast cancer) stadium 4 dan sudah metastase (menyebar) sampai ke paru-paru. Dokter mengatakan harapan hidup sangat kecil sekali. Ibu Ida sangat terpukul mendengar penjelasan dokter walaupun beliau sendiri juga sudah menyadari akan hidupnya tidak lama lagi. Yang sangat memberatkan pikiran dan hati si Ibu adalah anak-anaknya yang masih kecil-kecil, keadaan keluarga yang tidak berdamai dan ekonomi yang tidak memadai. Selama satu bulan peneliti mendampingi Ibu Ida untuk mempersiapkan dirinya menghadap sang pencipta-Nya. Dalam pendampingan tersebut peneliti selain menyampaikan.

Firman Tuhan dan puji-pujian, juga menjadi teman terbaik untuk mendengarkan curahan hati yang dialami dan juga memperbaiki hubungan keluarga yang hancur dan membawa mereka untuk saling mengasihi dan mengampuni. Ibu Ida 
sebelum menghembuskan nafasnya yang terakhir dapat tersenyum karena keluarganya sudah dipulihkan dan keluarga besarnya dapat mengurus anak-anaknya. Yang paling penting juga, keluarga besarnya mempercayai Tuhan yang akan menyertai keluarganya.

\section{METODE PENELIAN}

\section{Penelitian dilakukan di \\ Sebuah Yayasan kanker yang bernama Yayasan CAC (Cancer Awareness Community) Surabaya sejak September 2020 hingga Januari 2021. Penelitian melakukan metode kualitatif deskriptif karena penelitian mengupas pada satu sumber penelitian. Penelitian kualitatif yaitu penelitian yang digunakan untuk memilih pada kondisi objek yang alamiah dengan pendekatan deskriptif analisis, maksudnya adalah usaha memahami secara mendalam situasi di tempat penelitian dengan berdasar kepada informasi yang didapat} (Sugiyono, 2015).

Tentunya untuk mengukur keberhasilan dari praktik pastoral konseling di lapangan dimulai dengan teori yang dikumpulkan tentang prinsip-prinsip teori
(Chandra, 2019). Dan sasaran yang hendak dicapai adalah mampu menolong peneliti untuk mengamati, menganalisa kejadian-kejadian pada waktu penelitian dan menyampaikan informasi dengan menyeluruh mengenai apa fungsi pendampingan pastoral bagi pasien wanita dengan penyakit penderita kanker di Yayasan CAC Surabaya.

Dalam hal ini, peneliti menggunakan model oberservasi tidak terstruktur yaitu peneliti yang menggembangkan pengamatannya sesuai dengan pengamatan yang terjadi di lapangan (Prasanti, 2018).

Penelitian ini mempunyai tujuan untuk mengetahui Fungsi Pendampingan Pastoral bagi Pasien Wanita Penderita Kanker di Yayasan CAC Surabaya. Dalam penelitian ini ditemukan juga fakta bahwa dalam menjalankan fungsi mereka sebagai pendamping, para konselor/Pdt diperhadapkan dengan beberapa orang pasien yang menolak untuk didampingi dengan beberapa alasan.

Menurut para konselor penolakan disebabkan oleh beberapa faktor seperti sudah pernah 
DIEGESIS: Jurnal Teologi

Volume 6 No. 2, Agustus 2021.

mendapatkan pendampingan

sebelumnya, merasa takut karena

pernah berobat ke dukun, dan karena

berbeda keyakinan.

\section{Fungsi Pendampingan Pastoral}

\section{Bagi Pasien Wanita Penderita}

\section{Kanker diYayasan CAC.}

\section{Fungsi rekonsiliasi.}

Berdasarkan hasil temuan dari narasumber dapat disimpulkan bahwa seorang pendamping harus mampu membawa pasien untuk berdamai kembali dengan dirinya dan dengan Tuhan melalui pertobatannya, dan kembali menerima Yesus sebagai Juruselamatnya sehingga ia menjadi manusia yang seutuhnya.

\section{Fungsi Penyembuhan}

Menurut hasil penelitian yang diperoleh pendampingan yang dilakukan oleh konselor berfungsi untuk membawa perubahan dalam diri pasien dalam menghadapi sakitnya. Yang tadinya takut biopsy, takut kemoterapi, akhirnya mereka semua mau menjalani proses semua pengobatan. Meskipun diantara pasien di yayasan akhirnya ada yang meninggal dunia karena terlambat berobat.

\section{Fungsi Peneguhan}

Dalam pendampingan pastoral bukan hanya memiliki ukuran dari pasien yang dilayani, tetapi juga haruslah memiliki faktorfaktor yang mempengaruhi pasien penderita kanker untuk tetap semangat dalam menjalani hidup, diantaranya para pasien haruslah memiliki harapan dan masa depan di tangan Tuhan.

Melakukan pelayanan pribadi, doakan para pasien dan sampaikan Firman Tuhan kepada pasien bahwa mujizat kesembuhan masih tetap ada sampai saat ini. Serta harus tetap menjaga lingkungan sekitar pasien, agar pasien tetap selalu bersemangat untuk tetap hidup, dan juga dibutuhkan support dari keluarga maupun orang terdekat mereka (Gratia, 2020).

Tantangan Seorang Pendamping Dalam Melakukan Pendampingan Pastoral Bagi Pasien Wanita Penderita Kanker Di Yayasan CAC

Membangkitkan semangat dan harapan hidup pasien

Dalam Pendampingan 
Pastoral terhadap para pasien wanita penderita kanker di Yayasan CAC, tentunya tidak semudah yang dapat dipikirkan. Dalam kesaksiannya, seorang konselor mengatakan bahwa hambatan ataupun permasalahan yang sering mereka alami adalah tidak adanya semangat hidup dalam diri pasien, sehingga ini membutuhkan perhatian dan teknis khusus untuk membangkitkan semangat sehingga mereka mau untuk dilayani (Muryati, 2018).

Salah satu narasumber yang peneliti wawancara menceritakan bagaimana pengalaman beliau selama melakukan pendampingan bagi pasien di Yayasan CAC. Beliau adalah Pdt. Erickjon Panjaitan, beliau tamatan S1-Teologi dan menjadi seorang Konselor selama 11 tahun dan disimpulkan bahwa beliau sudah cukup lama dan berpengalaman dalam melakukan pendampingan pastoral di suatu yayasan penderita penyakit kanker.

Dalam kesaksiannya,
hambatan ataupun permasalahan yang dialami oleh Pdt. Erickjon Panjaitan adalah tidak adanya semangat hidup dalam diri mereka. Dan untuk mengatasi hal tersebut
Pdt Erick John memberikan sentuhan kasih kepada setiap pasien penderita kanker. Sebab sentuhan kasih yang diberikan akan berdampak kepada pasien dan akan membuat pasien untuk memiliki semangat baru dalam bertahan hidup dan juga memberikan semangat kepada pasien untuk tetap optimis bahwa kesehatan, kesembuhan masih tetap terjadi dalam hidupnya.

Peneliti juga melakukan wawancara kepada salah seorang dari Yayasan CAC Surabaya, menurut Ibu Duma Arta, bahwasanya seorang Pendamping Pastoral harus memiliki keterampilan dalam melayani pasien penderita Kanker, setidaknya mempunyai pengalaman hidup di sekitar penderita kanker, sebab pengalaman yang pernah pendamping alami dalam melayani pasien penderita kanker, maka hal itu dapat memberikan semangat dan harapan hidup buat para pasien.

Karena ada banyak para pendamping yang tidak punya pengalaman dalam pendampingan khususnya kepada penderita kanker sehingga ini bisa menjadi hambatan dalam proses konseling. Dan 
DIEGESIS: Jurnal Teologi

Volume 6 No. 2, Agustus 2021.

menurut pendapat Ibu Elisabeth

Meliana bahwasanya seorang pendamping pastoral juga harus menerapkan konsep pelayanan konseling yang benar bagi pasien penderita kanker, walaupun hal yang diterapkan belum tentu semuanya sempurna namun motivasi hatinya yang paling penting dalam melakukan pelayanan kepada pasien penderita kanker.

Meyakinkan pasien bahwa mujizat masih ada

Ada banyak pasien penderita kanker yang sudah apatis akan hidupnya dan sudah tidak percaya lagi akan mujizat. Karena itulah seorang pendamping harus mampu meyakinkan bahwa mujizat itu masih ada.

Mujizat adalah salah satu cara Allah untuk menyatakan dirinya kepada manusia. Dengan mempercayai mujizat itu nyata berarti membuka diri untuk memberi Tuhan jalan melakukan hal-hal ajaib dalam hidup kita. Melalui Mujizat bisa dibuktikan bahwa logika dan kemampuan manusia tidak ada artinya dibandingkan dengan kuasa Allah (Hosea, 2019).

Peneliti juga mewawancarai salah satu dari pasien yakni adalah
Ibu Ratna pada 6 September 2020 yang ada di Yayasan CAC Surabaya, bahwasanya menurut Ibu Christine Elim untuk meyakinkan pasien bahwa mujizat masih ada sampai saat ini, yaitu maka seorang pendamping pastoral haruslah menjadi panutan dalam hidupnya dalam hal iman dan juga kehidupannya mencerminkan pribadi Kristus. Sedangkan menurut Ibu Duma Arta R. Sitinjak, yang merupakan salah satu orang Yayasan mengatakan yang harus dilakukan Pendamping Pastoral adalah memotivasi penderita untuk terus semangat dan memberikan firman Tuhan yang merupakan sebagai penguat bagi rohaninya dan juga mengarahkan pasien untuk pola hidup sehat.

\section{Menuntun pasien untuk percaya}

\section{kuasa doa}

Doa memiliki fungsi penting dalam keberlangsungan dan perjalanan kehidupan manusia. Dalam setiap perjalanan waktu hidup manusia yang percaya kuasa doa, mereka selalu akan melakukan aktifitas dengan doa sebelum melaksanakan pekerjaannya agar mereka memperoleh keselamatan dan 
kesejahteraan. Dalam berdoa terjadi komunikasi antara pendoa dengan Allah yang tentunya dilandasi dengan cinta kasih kepada Allah. Sebagaimana yang dikatakan oleh Vellanickal bahwa dalam doa terjadi dialog antara Allah dan manusia dimana Allah dan manusia saling berjumpa dan mengenal satu sama lain.

Seorang pendamping pastoral haruslah memiliki syarat-syarat yang baik, antara lain adalah seorang yang sudah sering melakukan pelayanan di dalam gereja, sehat jasmani dan rohani, dapat menjadi panutan dalam iman dan kehidupannya mencerminkan pribadi Kristus, pendengar yang baik dan punya empati dimana pendamping bisa menempatkan dirinya sebagai penderita, bukan hanya memberi wejangan, bisa mendukung secara mental spiritual, sabar dan menjadi pendengar yang baik, telaten serta kerohaniannya tinggi. Dan dari semuanya itu haruslah datang dari hati yang mau melayani, dan itulah paling penting di luar dari pengetahuan kita mengenai kanker dan Pengobatannya.

\section{Membangkitkan Iman pasien melalui Firman}

Dari setiap pasien yang dilayani, tentulah semuanya tidak sama permasalahan yang dihadapi. Apabila dari pasien mengalami permasalahan dalam hal hilangnya semangat hidup yang dialami mereka, maka konselor haruslah melayani para pasien dengan sentuhan kasih, membangkitkan iman si penderita melalui pendengaran Firman Tuhan yang disampaikan. Sebagaimana yang tertulis dalam Alkitab: iman timbul dari pendengaran, dan pendengaran oleh Firman Allah (Rm. 10:17). Bahwa ketika si penderita sering mendengar Firman Tuhan disampaikan, maka imannya akan semakin dikuatkan dan dibangkitkan. Lalu seorang konselor juga haruslah menjadi seorang pendengar yang baik, selalu mendoakan pasien, mengajak berdoa bersama, tidak membicarakan hal-hal yang berat dan selalu mengajak pasien melakukan hal-hal yang disukai. Karena itu, dalam melakukan tindakan ibadah dan pendampingan mesti kreatif sesuai dengan kebutuhan konsili (Untung et al., 2021). 
Peneliti melakukan wawancara kepada salah satu pasien di Yayasan CAC Surabaya, dan menurut Ibu Christine Elim, bahwasanya seorang pendamping pastoral memiliki fungsi dalam pelayanannya. Sehingga melalui pelayanannya dapat membangkitkan iman daripada pasien. Oleh karena itu dalam pelayanan Pendampingan Pastoral tentulah memiliki tujuan utama dalam melayani para pasien, diantaranya adalah menjadikan pasien memiliki iman yang kuat dalam Tuhan, membawa pasien pada pengakuan bahwa hanya Tuhanlah sumber kekuatan, pengharapan dan kehidupan kekal, menemani dan memberikan semangat ataupun support kepada pasien, mendukung secara mental dan spiritual, sehingga pasien merasa tidak sendirian. Sedangkan menurut Ibu Theresia Pangemanan bahwasanya seorang pendamping pastoral haruslah membangkitkan iman pengharapan pasien kepada Tuhan sebab Tuhan adalah sebagai sumber kekuatan dan kesembuhan sesuai dengan rencanaNya.

\section{HASIL DAN PEMBAHASAN}

\section{Fungsi Pendampingan Pastoral Bagi Pasien Wanita Penderita Kanker diYayasan CAC}

\section{Fungsi rekonsiliasi}

Rekonsiliasi adalah sebuah peristiwa perbaikan/pemulihan hubunganantara Allah dan manusia yang tadinya rusak melalui korban Yesus di Kayu Salib (Christi, 2012). Semua orang telah dipulihkan dan menjadi suci karena adanya perdamaian antara manusia dengan Allah. Peristiwa rekonsiliasi tersebut merupakan karya keselamatan Allah yang luar biasa. Kristus melalui pengorbananNya, manusia telah didamaikan dengan Allah dan melalui kuasa Roh Kudus diberikan kemampuan untuk berdamai dengan yang lain. Perdamaian (rekonsiliasi) merupakan hadiah dan berkat Allah untuk ciptaan-Nya. Hal ini akan membawa kepada kehidupan yang dapat menjadi segambar dan serupa dengan Tuhan.

Rekonsiliasi sangat membantu pendamping pastoral untuk dapat menyelesaikan masalah yang dialami penderita kanker baik dalam hubungannya dengan sesama maupun anggota keluarga. Rekonsiliasi sangatlah diperlukan di setiap 
pelayanan di dalam gereja, guna mengatasi sesuatu dan akibat konflik sebagai usaha untuk mencapai pendamaian. Menurut E.B. Surbakti dalam bukunya Benarkah Injil Kabar Baik? Fungsi rekonsiliasi adalah usaha manusia memperbaiki hubungan yang rusak baik antara dirinya dengan orang lain dan antara dirinya dengan Tuhan. Perdamaian ini berasal dari perdamaian Yesus atas dosa manusia. Dosa merupakan pemberontakan manusia terhadap Allah dan putusnya relasi imannya dengan Allah (Surbakti, 2005).

\section{Fungsi Penyembuhan}

\section{Penyembuhan penyakit Kanker}

Dalam proses penyembuhan penyakit kanker maka rumah singgah sangatlah dibutuhkan mengingat proses pengobatan yang cukup panjang. Menurut Siti Sudarni bahwa adanya rumah singgah sangat bermanfaat bagi penderita kanker yang sedang dalam proses penyembuhan penyakit kanker, dimana ketika berada di rumah singgah pasien dan pendamping dapat menikmati kegunaan rumah singgah baik secara fisik, psikologis, spiritual dan sosial (Sudrani \& Sutaryo, 2017).

\section{Penyembuhan Psikologis}

Dalam proses penyembuhan penderita penyakit kanker, faktor psikologis memegang peranan yang cukup besar bahkan merupakan faktor yang sangat penting, karena faktor psikologis khususnya kesehatan jiwa pasien ternyata bisa membantu pasien untuk bisa menyembuhkan penyakitnya. Penyembuhan psikologis bagi pasien dengan penyakit kanker dilakukan untuk mengurangi tingkat kecemasan, menghilangkan perasaan depresi, kehidupan sosial, dukungan keluarga, komunikasi yang lancar, kepercayaan pasien pada diri sendiri, mempercayai penanganan medis dokter, kehidupan religius, berpikir positif, dan pola hidup yang baik.

\section{Penyembuhan Spiritual \\ Fungsi penyembuhan yaitu} untuk menolong pasien agar mampu mengobati masalah psikologis dan spiritual yang cukup berat dalam menghadapi penyakit kanker yang mereka hadapi. Fungsi penyembuhan secara spiritual ini juga berfungsi untuk menolong pasien supaya dapat meningkatkan 
DIEGESIS: Jurnal Teologi

Volume 6 No. 2, Agustus 2021.

kualitas iman dan kepercayaannya pada Tuhan.

Proses kesembuhan ini dititik beratkan kepada sisi kerohanian kehidupan manusia dan berhubungan dengan kesehatan jasmani manusia umumnya dan secara khusus kesehatan mental manusia, secara menyeluruh atau utuh (Endra, 2014). Disamping soal kesembuhan, seorang pendamping pastoral juga harus menyiapkan penderita pasien kanker untuk siap menghadapi yang namanya kematian. Pasien dibawa kepada suatu realita dan kenyataan bahwa Tuhan lah yang empunya kendali dalam kehidupan kita termasuk kesembuhan (Haliman, 2005).

\section{Fungsi peneguhan}

Fungsi peneguhan berfungsi membantu pendamping pastoral untuk menghadapi pasien yang sedang mengalami permasalahan bahkan mungkin kehilangan pengharapan. Clinebell mengatakan fungsipeneguhan bagi pendamping pastoral sangat membantu untuk memberikan dukungan moral terlebih khusus spiritual pada pasien pengidap penyakit yang menghadapi masalah dan kehilangan pengharapan, supaya pasien tetap kuat dan optimis dalam menjalani hidupnya (Clinebell, 2006).

\section{SIMPULAN}

Berdasarkan penelitian ini dapat disimpulkan bahwa pelayanan pendampingan pastoral sangatlah diperlukan dalam sebuah Yayasan kanker, dikarenakan agar pasien yang ada dapat dikuatkan dan terhibur serta diberikan semangat hidup oleh setiap konselor yang melayani mereka. Pendampingan pastoral dalam melayani pasien wanita penderita kanker bagi penderita kanker tentulah memiliki fungsi didalamnya, diantaranya adalah sebagai penguat iman dan support karena pasien kanker sering merasakan down/ lemah, sumber kekuatan dan kesembuhan sesuai dengan rencanaNya melalui iman pengharapan kepada Tuhan, memberikan dukungan dalam mengontrol emosi pasien (secara moral) dan juga pengetahuan tentang pengobatan yang benar, mendoakan serta memberikan semangat sebagai orang terdekat pasien untuk sharing ataupun sebagai tempat curahan hati para pasien. 
Peranan seorang pendamping pastoral sangat berguna sekali bagi setiap hidup para pasien penderita kanker. Sebab seorang pendamping pastoral juga menguatkan pasien melalui Firman Tuhan yang dibagikan sehingga membangkitkan iman setiap para pasien dan membawa pasien semakin dekat kepada Tuhan. Sebab di dalam Tuhanlah segala kekuatan kita dapatkan.

\section{DAFTAR PUSTAKA}

Cemy, F. N. (2012). Palliative Care Pada Penderita Penyakit Terminal. Gaster | Jurnal Ilmu Kesehatan, 7(1), 527-537.

Chandra, D. C. (2019). FUNGSI TEORI DALAM METODE PENELITIAN KUALITATIF. Reseach Gate.

Christi, A. M. (2012). Pengudusan Orang Percaya. In Pemikiran Teolog Gereja Bethel Indonesia tentang Teologi Pentakosta (pp. 151-171). STT Bethel Indonesia.
Clinebell, H. (2006). Tipe-Tipe Dasar Pndampingan dan Konseling Pastoral. BPK Gunung Mulia.

Endra, F. (2014). Pendekatan Pelayanan Kesehatan Dokter Keluarga: Pendekatan Holistik Komprehensif. Zifatama Jawara. Gratia, Y. P. (2020). Ulasan Buku Daniela C . Augustine: Pentecost , Hospitality and Transfiguration-Toward A Spirit-Inspired Vision of Social Transformation. Diegesis: Jurnal Teologi, 5(1).

Haliman, A. (2005). Seteguk Air di Kala Dahaga, Kumpulan Renungan Pasien dan Pelayanan Kesehatan. Kanisius. Hosea, A. (2019). Karakteristik Pendidikan Iman dalam Pentakostalisme. Diegesis: Jurnal Teologi, 4(2), 51-57. Johni Hardori. (2014). The Lost of Pastoral Ministry. In Reaffirming our Identity (p. 285). STT Bethel Indonesia.

Khosidah, A., \& Trisnawati, Y. (2015). Faktor-faktor yang Mempengaruhi Ibu Rumah Tangga dalam Melakukan Tes IVA sebagai Upaya Deteksi Dini Kanker Serviks. Jurnal Ilmiah 
Kebidanan, 6(2), 94-105.

http://download.garuda.ristekdi

kti.go.id/article.php?article=433

$659 \&$ val $=6633 \&$ title $=$ DETER

MINAN FAKTOR YANG

MEMPENGARUHI IBU

RUMAH TANGGA DALAM

MELAKUKAN TES IVA

SEBAGAI UPAYA DETEKSI

DINI KANKER SERVIKS

Kiesser, B. (1984). Ikut Menderita

Ikut Percaya: Pastoral Orang

Sakit. Yayasan Kanisius \& Nusa

Indah.

Kusmaryanto, C. B. (2021). Bioetika.

In GEPCOMM Diagnostic

Essay (3rd ed.). Kompas:

Penerbit Buku.

Maharani, S. (2013). Kanker:

Mengenal 13 jenis Kanker dan

Pengobatannya. Katahati.

Muryati. (2018). Recovering from

Grief: Pendampingan Pastoral bagi Penderita Penyakit

Terminal. STT Bethel Indonesia. Muryati, Setianto, Y., Benyamin, P. I., \& Nasution, A. F. N. (2020). Strategi Mengatasi Kemarahan melalui Perumpamaan Berdasarkan Yunus 4. Jurnal Teologi Gracia Deo, 3(1), 1423.
Nugroho, F. J. (2017). Pendampingan

Pastoral Holistik: Sebuah

Usulan Konseptual Pembinaan

Warga Gereja. Evangelikal:

Jurnal Teologi Injili Dan

Pembinaan Warga Jemaat, 1(2), 139.

https://doi.org/10.46445/ejti.v1i

2.71

Pakpahan, G. (2020). Kecemasan Mahasiswa STT Bethel Indonesia terhadap Covid-19. Jurnal Pendidikan Agama Kristen, 3(1), 20-33.

Pakpahan, G. K. R. (2020). Analysis of Worring among Lecturers of Indonesian Bethel Theology on Covid-19. Medico-Legal Update, 20(4), 1330-1337. https://doi.org/10.37506/mlu.v2 $0 \mathrm{i} 4.2014$

Prasanti, D. (2018). Penggunaan Media Komunikasi Bagi Remaja Perempuan Dalam Pencarian Informasi Kesehatan. LONTAR: Jurnal Ilmu Komunikasi, 6(1), 13-21.

https://doi.org/10.30656/lontar.v $6 \mathrm{i} 1.645$

Romas, R. (2017). Pendampingan Pastoral orang Menjelang Ajal. Jurnal Sepakat, 3(2), 178-204. 
Storm, M. B. (2000). Apakah Pengembalana Itu? BPK Gunung Mulia.

Sudrani, S., \& Sutaryo, S. (2017). Manfaat rumah singgah bagi pasien kanker. Berita Kedokteran Masyarakat, 35(4), 4.

Sugiyono. (2015). Metode Penelitian Kualitatif dan $\mathrm{R}$ and $\mathrm{D}$. In Bandung: Alfabeta. Alfabeta.

Sumarno, Y. (2012). Pelayanan Bimbingan dan Konseling di Sekolah. Edukasi: Jurnal Pendidikan Agama Kristen, 4(1), 123-145.

Sumual, I. S. (2016). Potret Perempuan Gereja dalam Berbangsa. In Bergereja dalam Bingkai Kebangsaan. STT Bethel Indonesia.

Surbakti, E. B. (2005). Benarkah Injil Kabar Baik? BPK Gunung Mulia.

Untung, N., Tanonggi, R. O., \& Pekuwali, J. R. (2021). Komsel Pemuridan Kreatif Pemuda GBI Bukit Sion. Jurnal PKM Setiadharma, 1(1), 91-99.

Wiryasaputra, T. S., \& Handayani, R. (2013). Pengantar Kedalam
Konseling Pastoral. Asosiasi Konselor Pastoral Indonesia. Yafie, A. (1998). Sakit Menguatkan Iman - Uraian Pakar Medis dan Spiritual. Gema Insani Pers. 